\title{
Romanticismo y romanticismos en los grabados de la revista artística No Me Olvides (1837-1838)
}

\author{
Romanticism ans Romanticisms in the engravings \\ of the Artistic Magazine No Me Olvides (1837-1838)
}

María Victoria ÁLVAREZ RODRÍGUEZ

Universidad de Salamanca

Recibido: 6-IV-2017

Aceptado: 10-VII-2017

RESUMEN: Durante los primeros años del reinado isabelino asistimos en España al surgimiento de las publicaciones periódicas dedicadas a las Bellas Artes. Estrechamente relacionadas en la década de 1830 con el Romanticismo que estaba empezando a calar en el país, con el paso de los años acabaron convirtiéndose en unas revistas menos exaltadas cuya gran aspiración era atraer a un número cada vez mayor de lectores. La revista No Me Olvides fue una de las que mejor recogió esos arrebatados postulados de los escritores y artistas del primer Romanticismo, algo apreciable tanto en sus textos como en los grabados que los acompañaban. En el presente artículo abordaremos el análisis de dichas estampas atendiendo al acercamiento de cada grabador a un romanticismo distinto, moviéndose entre la herencia del academicismo, el costumbrismo, el goticismo o el sentimentalismo. Grabado.

Palabras clave: Romanticismo, España, Siglo XIX, Isabel II, Historiografía artística, Prensa artística, No Me Olvides,

ABSTRACT: During the first years of the reign of Isabel II we witnessed in Spain the emergence of periodicals dedicated to fine arts. Closely related in the 1830 s with the Romanticism that was beginning to spread in the country, over the years ended up becoming less exalted magazines whose great aspiration was to attract an increasing number of readers. The magazine No Me Olvides was one of those that best collected the impassioned postulates of the writers and artists of the first Romanticism, something appreciable both in their texts and in the engravings that accompanied them. In the present article we will analyze these prints taking into account the approach of each engraver to a different romanticism, moving between the inheritance of academicism, the costumbrism, the gothicism or the sentimentalism.

Keywords: Romanticism, Spain, 19th century, Isabel II, Art historiography, Art press, No Me Olvides, Engraving.

\section{INTRODUCCIÓN}

Si analizamos las grandes aportaciones que se dieron en la Europa decimonónica al ámbito de la historiografía artística, comprobaremos que uno de los cambios más llamativos fue el enorme desarrollo de la expresión gráfica en dicha centuria. El siglo XIX fue el siglo del progreso, de la inmediatez, de la modernidad; y los avances que se die- ron en el campo del grabado acabaron haciendo de él uno de los mejores medios para mostrar a la sociedad cómo era el mundo. La abrumadora difusión de imágenes que se llevó a cabo en los periódicos, cada vez más variados y numerosos, contribuyó a crear una nueva manera de pensar que encontraba en las estampas la condensación perfecta de lo que se quería transmitir. Estas no se limi- 
taron, en consecuencia, a mostrar las transformaciones que se estaban produciendo en el mundo, sino que desempeñaron un papel determinante moldeándolo conforme a la inmediatez de los parámetros modernos ${ }^{1}$.

Evidentemente, una de las razones por las cuales el grabado experimentó tal auge en la centuria decimonónica fue la paulatina conquista de la libertad de prensa que tuvo lugar en las primeras décadas. En el caso español, hubo que esperar hasta la muerte de Fernando VII para que los avances que se estaban produciendo al respecto en los demás países se dejaran sentir también en suelo patrio, dado que el monarca era de la opinión de que cualquier influencia procedente del extranjero podía suponer una amenaza para su gobierno. De ahí que hasta el reinado de su hija Isabel II, entre 1833 y 1868 , no fueran aprobadas las primeras medidas que permitieron la creación, consolidación y proliferación de las publicaciones periódicas, como la Ley de Prensa de 1837, aprobada durante la regencia de su madre María Cristina de Borbón-Dos Sicilias entre 1833 y 1840, la Ley Nocedal de 1857 o la Ley de Cánovas de $1864^{2}$. Cabe mencionar que aun así existió una considerable censura en lo referente a las alusiones a la monarquía, el Gobierno y la Iglesia, si bien las revistas artísticas que empezaron a ver la luz a partir de 1835 gozaron de una mayor permisividad por ocuparse de temas "inofensivos" a ojos de los censores.

Este tipo de revistas solían poseer un carácter poliédrico durante los primeros años del reinado isabelino, publicando artículos sobre arquitectura, escultura, pintura, viajes

${ }^{1}$ C. ROSEN y H. ZERNER, Romanticismo y realismo. Los mitos del arte del siglo XIX, Madrid, 1988, p. 49. Para profundizar en las circunstancias que rodearon al auge de la estampa en la España decimonónica remitimos a V. BOZAL, La ilustración gráfica del siglo XIX en España, Madrid, 1979.

${ }^{2}$ M. Á. BLANCO MARTÍN, “Opinión pública y libertad de prensa (1808-1868)", en J. SIMOZ DÍAZ (coord.), La prensa española durante el siglo XIX. I Jornadas de especialistas en prensa regional y local, Granada, 1988, p. 43. por el extranjero, exposiciones, necrológicas de artistas, etc. al tiempo que hablaban de literatura, teatro, música o eventos sociales. Fuertemente influenciadas por los modelos franceses que empezaron a circular por España tras el fallecimiento de Fernando VII, la mayoría de estas publicaciones adoptaron un carácter burgués con el que se pretendía llegar al gran público, diferenciándose de este modo de las feuilles d'annonces centradas en la práctica arquitectónica que solo comenzaron a calar en nuestro país a partir de la creación de Boletín Español de Arquitectura $(1846)^{3}$. Como no podía ser de otro modo, también imitaron a sus homólogas francesas en la incorporación de numerosos grabados que acompañaban a los textos, al principio tomados directamente de las extranjeras y más tarde, conforme se produjo la consolidación de la xilografía sobre madera, mucho más rápida y barata que la litografía sobre piedra, realizados por la primera generación de grabadores españoles especializados en esta técnica. Pronto quedó demostrado que la estampa era un elemento sine qua non en las publicaciones dedicadas a las Bellas Artes, puesto que a la larga contribuyeron tanto como los textos, si no más, a dar a conocer al conjunto de la sociedad los monumentos que mejor definían la esencia de lo español ${ }^{4}$.

Puede apreciarse, no obstante, una evolución muy clara en esas revistas: mientras que en la década de 1830 asistimos al surgimiento de las primeras publicaciones de corte romántico, a menudo bastante exaltadas y dirigidas por un colectivo de artistas jóvenes, en las de 1840 y 1850 ese carácter

\footnotetext{
3 Á. ISAC, Eclecticismo y pensamiento arquitectónico en España. Discursos, revistas, congresos (1846-1919), Granada, 1987, pp. 111-112 y E. HURTADO TORÁN, Las publicaciones periódicas de Arquitectura, Madrid, 2001, pp. 59-71.

${ }^{4}$ Sobre esta cuestión son de obligada referencia L. ROMERO TOBAR, Panorama crítico del romanticismo español, Madrid, 1994; I. HENARES CUÉLLAR y J. CALATRAVA, Romanticismo y teoría del arte en España, Madrid, 1982 y J. E. GARCÍA MELERO, Literatura española sobre artes plásticas, II, Bibliografía aparecida en España durante el siglo XIX, Madrid, 2002.
} 
sentimental se fue atenuando dando paso a un tipo de revista más aburguesada, enciclopédica y dirigida al gran público, desembocando en la de 1860, finalmente, en un prototipo mucho más positivista, riguroso y científico. Esta evolución no es sino un reflejo de los cambios culturales producidos en España durante el reinado de Isabel II, pasando en el transcurso de esas cuatro décadas de la mentalidad romántica a la positivista de ascendencia naturalista que, en lo tocante a disciplinas como la Historia, la Historia del Arte o la Arqueología, perseguía equipararlas a otras ramas del saber tradicionalmente científicas como la Botánica, la Zoología o la Mineralogía ${ }^{5}$.

Sin embargo, también saltan a la vista las diferencias existentes entre las revistas dentro de cada una de las tres etapas que hemos citado, especialmente en cuanto a sus respectivos idearios, sus temas de mayor interés y los posicionamientos metodológicos que adoptaron para abordar su análisis. Como comprobaremos en el presente estudio, la publicación No Me Olvides, dirigida entre 1837 y 1838 por el poeta Jacinto de Salas y Quiroga, fue sin duda la más romántica de todas las que vieron la luz en la primera etapa, tanto en lo relativo a los artículos como a sus estampas. En estas puede apreciarse asimismo cómo ese primer Romanticismo aún seguía siendo titubeante, con cada uno de los grabadores que formaron parte del equipo de Salas y Quiroga mostrando una asimilación distinta de los postulados que estaban empezando a calar en el país.

\section{NO ME OLVIDES (1837-1838)}

Esta publicación constituye uno de los ejemplos más elocuentes de las revistas de comienzos del reinado isabelino que, pese a dejar de publicarse antes de cumplir un año de vida y de contar con un número de suscriptores decididamente exiguo, acabaron convirtiéndose a ojos de la historiografía ar-

${ }^{5}$ J. PLAZAOLA, Modelos y teoría de la Historia del Arte, San Sebastián, 2009, p. 40. tística del siglo XX en la perfecta plasmación de la manera en que arraigó el Romanticismo temprano en nuestro país. En efecto, de No Me Olvides solo se publicaron cuarenta y una entregas entre el 7 de mayo de 1837 y el 11 de febrero de 1838, pero en aquel lapso de tiempo Jacinto de Salas y Quiroga y su equipo supieron otorgarle una personalidad mucho más definida, exaltada $\mathrm{y}$, al mismo tiempo, coherente que la de predecesoras como El Artista (1835-1836). Como veremos a continuación, el hecho de que fuera la más original de las revistas que vieron la luz en aquella década y la que mejor defendió los ideales encarnados por la juventud no solo se aprecia en sus artículos sobre Bellas Artes, algunos de los cuales resultaron realmente revolucionarios para la época, sino también en el aliento romántico de sus ilustraciones ${ }^{6}$.

Resulta imposible desligar esa personalidad tan propia de la de Salas y Quiroga teniendo en cuenta que surgió de su deseo de crear una tribuna desde la cual difundir los ideales románticos, con los cuales comulgó durante toda su trayectoria, entre los jóvenes españoles después de que se produjera el ocaso de El Artista. Nacido en La Coruña, sus años de estudiante resultaron bastante azarosos: tras la muerte de su padre se trasladó a Madrid, de ahí se marchó unos años a Burdeos y a los diecisiete emigró a Lima, donde comenzó su carrera como poeta y dramaturgo. No pudo regresar a España hasta 1832, momento en que lo encontramos instalado en la capital y participando activa-

\footnotetext{
${ }^{6}$ I. TAJAHUERCE ÁNGEL, El arte en las revistas ilustradas madrileñas (1835-1840), Tesis doctoral defendida en la Universidad Complutense de Madrid, 2004, pp. 149-150. Para profundizar en el estudio de esta revista remitimos a M. E. RINCÓN CALERO, Las Fuentes del Romanticismo en España: No Me Olvides. Periódico de Literatura y Bellas Artes, Tesis doctoral defendida en The Ohio State University (en línea), consultado el 31 de marzo de 2017. URL: https://etd.ohiolink.edu/!etd. send_file?accession $=$ osu $1243974459 \&$ disposition=inline e ÍDEM, "Periodismo y literatura en el Romanticismo. El periódico literario No Me Olvides (1837-1838)", en J. M. RODRÍGUEZ RODRÍGUEZ y M. ANGULO EGEA (coords.), Periodismo literario: naturaleza, antecedentes, paradigmas y perspectivas, Madrid, 2010, pp. 71-87.
} 
mente en el ambiente romántico del Ateneo, además de involucrarse en empresas periodísticas como la de El Artista (entre 1835 y 1836) y fundar el No Me Olvides (entre 1837 y 1838). No obstante, su estancia en Madrid no le haría renunciar a los largos viajes: tras la extinción de su propia revista volvió a marchar al extranjero en distintas ocasiones, gracias a un cargo diplomático que le llevó en 1839 a Puerto Rico y más tarde, en 1842, a Holanda? .

Analizando su producción literaria, salta a la vista que Salas y Quiroga fue uno de los autores que más predicó con el ejemplo a la hora de dar a conocer los ideales de la nueva estética romántica. No en vano se considera a su obra Poesías, un recopilatorio de composiciones poéticas de juventud publicado en 1834, uno de los grandes manifiestos del Romanticismo español, coincidiendo con otros hitos semejantes como el estreno de $L a$ conjuración de Venecia de Francisco de Paula Martínez de la Rosa o Macías de Mariano José de Larra. Esa implicación vital con la poesía, que le llevó a afirmar que su profesión era "un sacerdocio de moralidad y de virtud", vuelve a percibirse en otras obras como Claudia (1834), Viages: isla de Cuba (1840), Ensayos poéticos (1845), Los habitantes de la luna (1847) y El Dios del siglo (1848), si bien es cierto que su temprana adscripción a este movimiento le llevó a abusar de recursos que acabarían convirtiéndose en los clichés románticos por excelencia, como el amor no correspondido, la magnificencia de la naturaleza, la insignificancia del hombre, etc ${ }^{8}$.

\footnotetext{
${ }^{7}$ G. TORRES NEBRERA, "Salas y Quiroga, Jacinto de", en Diccionario Biográfico Español, XLV, Madrid, 2013, pp. 186-187; R. P. SEBOLD, “Jacinto de Salas y Quiroga, poeta huérfano, cosmopolita y romántico", Salina. Revista de Lletres, no 23, 2009, p. 67 y M. E. RINCÓN CALERO, "De la ficción a la historia: la biografía del viajero romántico Jacinto de Salas y Quiroga", Crítica hispánica, Vol. XXXI, nº 2, 2009, pp. 187-203.

${ }^{8}$ G. TORRES NEBRERA, "La poesía del bardo sombrío Salas y Quiroga", en Aún aprendo. Estudios dedicados al profesor Leonardo Romero Tobar, Zaragoza, 2012, pp. 259-268.
}

También el prospecto incluido el 1 de mayo de 1837 en el primer número de No Me Olvides acabó convirtiéndose en una suerte de oriflama para las primeras plumas del Romanticismo español. Manteniéndose en la misma línea que en sus Poesías, Salas y Quiroga describía esta nueva sensibilidad como "un manantial de consuelo y pureza, el germen de las virtudes sociales, el paño de las lágrimas que vierte el inocente, el perdón de las culpas, el lazo que debe unir a todos los seres" ${ }^{\prime \prime}$. Estos ideales eran compartidos por la inmensa mayoría de sus colaboradores, a los que unían tanto el entusiasmo como la juventud; muchos de ellos, de hecho, habían colaborado previamente en El Artista y tras su desaparición pasaron a engrosar las filas de Salas y Quiroga, si bien la revista de este último se implicó mucho más con el credo del movimiento. A nuestro juicio, una de las principales diferencias entre ambas es que $E l$ Artista se consideraba a sí mismo un símbolo de lo romántico pero solo lo era en cuanto a las cuestiones literarias, mientras que No Me Olvides también lo fue en cuanto al arte pese a que, en el momento en que empezó a salir a la calle, la impronta clasicista seguía estando mucho más arraigada en este ámbito que en el de la literatura. En cualquier caso, además de contar con Eugenio de Ochoa y Federico de Madrazo, los directores de $E l$ Artista, Salas y Quiroga atrajo a su proyecto a otros autores de la misma generación como Pedro de Madrazo, José Zorrilla, Juan Eugenio Hartzenbusch o Manuel de Assas, además de contar en el apartado gráfico, como veremos, con el citado Federico de Madrazo y Calixto Ortega Matamoros ${ }^{10}$.

Centrándonos en las características técnicas de la publicación, nos encontramos ante una revista de periodicidad semanal, lo más habitual entre las que vieron la luz en

\footnotetext{
9 J. DE SALAS Y QUIROGA, "Prospecto", No Me Olvides, $\mathrm{n}^{\circ}$ 1, 7 de mayo de 1837, p. 2.

${ }^{10}$ P. CABAÑAS, No me olvides (Madrid, 1837-1838), Colección de índices de publicaciones periódicas dirigida por Joaquín de Entrambasaguas, II, Madrid, 1946, p. 8 e I. TAJAHUERCE ÁNGEL, Op. cit., p. 8.
} 
esta etapa, que salía a la venta cada domingo a diez cuartos mientras que el precio de la suscripción mensual era de cuatro reales para los residentes en Madrid y cinco para los de las provincias. En el prospecto de Salas y Quiroga del que ya hemos hablado se especificaba que el primer número sería publicado el 1 de mayo de 1837, si bien esto no se produjo hasta una semana más tarde, el 7 del mismo mes, por causas desconocidas.

Cuando comenzó a publicarse lo hizo con el subtítulo Periódico de Literatura y Bellas Artes, aunque su nombre cambiaría a lo largo de sus escasos meses de vida. Al comenzar el año de 1838 pasó a llamarse No Me Olvides: Periódico Semanal en un claro intento de Salas y Quiroga de ampliar el abanico de sus potenciales lectores, tratando de imitar la personalidad poliédrica, enciclopédica y eminentemente divulgativa de revistas como Semanario Pintoresco Español que, por esas mismas fechas, estaban empezando a gozar de un enorme éxito. En cuanto a la elección de No Me Olvides como título, se trató de una decisión personal de Salas y Quiroga que, una vez más, puso de manifiesto su absoluta adhesión al credo romántico, al aludir a una obra del poeta José Joaquín de Mora titulada "A la flor llamada en inglés Forget me not (no me olvides)" e incluida en el primer número de la revista. Mora fue asimismo autor de una serie de almanaques titulada No $\mathrm{Me}$ Olvides o Colección de composiciones en prosa $i$ verso, orijinales o traducidas durante su exilio londinense entre 1824 y 1826 por encargo del editor Rudolph Ackermann ${ }^{11}$. Mediante esta referencia, Salas y Quiroga pretendía homenajear a aquellos intelectuales que, al acabar el Trienio Liberal, no tuvieron más remedio

${ }^{11}$ P. CABAÑAS, Op. cit., pp. 11-12 y L. MONGUIÓ, Don Jose Joaquin de Mora, Los Angeles, 1967, p. 12. El importante papel desempeñado por este predecesor del periódico de Salas y Quiroga, cuya traducción al español le permitió darse a conocer en países hispanoamericanos, ha sido estudiado por E. PAJARES INFANTE, "Traducción en la emigración. Pablo de Mendibil y su No me olvides de 1828 ", en C. PALACIOS BERNAL, F. LAFARGA y A. SAURA SÁNCHEZ (coords.), Neoclásicos y románticos ante la traducción, Murcia, 2002, pp. 73-88. que exiliarse al extranjero como consecuencia de sus ideas progresistas, actuando desde sus países de acogida (sobre todo Francia e Inglaterra) como importantes difusores del Romanticismo que estaba empezando a surgir en ellos.

En lo tocante a la impresión, esta se llevaba a cabo en la Imprenta de Francisco Pascual situada en el número 36 de la calle de Jardines, que pasó a convertirse también en sede de la redacción; por su parte, las estampas de las que hablaremos en el siguiente apartado salieron de la Litografía de Barrionuevo. Las páginas poseían un formato en $8^{\text {o }}$ de 210 milímetros de alto por 140 milímetros de ancho que permaneció inalterable en los cuarenta y un números de la publicación, con el texto organizado en dos columnas e intercalado con pequeños grabados de carácter decorativo. En opinión de Cabañas, es probable que Salas y Quiroga planeara formar tomos de naturaleza semestral con los números publicados, tal como se había hecho años antes con El Artista, de ahí que al frente del número 27, correspondiente al 5 de noviembre de 1837, aparecieran escritas las palabras "Tomo II". No obstante, conviene tener en cuenta que esos volúmenes no tendrían la misma extensión si los ordenáramos actualmente de este modo debido al temprano ocaso de No Me Olvides: el primero sería de 208 páginas y el segundo de $120^{12}$.

Dicho ocaso se produjo por motivos similares a los del resto de revistas artísticas que vieron la luz por entonces. Esencialmente, el hecho de que No Me Olvides estuviera dirigido a un público muy concreto, formado por profesionales de las artes y las letras y amantes de las mismas, le impidió alcanzar un número de lectores tan elevado como el de aventuras periodísticas más exitosas como el recién fundado Semanario Pintoresco Español. Ya hemos explicado que el director trató de redirigir el rumbo del rotativo en sus últimos meses, si no modificando sustancialmente su contenido, sí añadiendo aquel subtítulo de Periódico Semanal que lo hiciera

\footnotetext{
${ }^{12}$ P. CABAÑAS, Op. cit., p. 10
} 
asemejarse más a las revistas de carácter enciclopédico. Parece, en cualquier caso, que la que nos ocupa estaba sentenciada desde mucho antes de su desaparición: en un artículo titulado "Habladurías" que vio la luz el 27 de agosto de 1837, todavía en el primer año de la revista, Salas y Quiroga plantaba cara a aquellos que aseguraban que no contaban con suficientes suscriptores como para seguir adelante, aunque cuando finalmente dejó de publicarse, el 11 de febrero del año siguiente, no dio ninguna explicación al respecto.

Sea como fuere, la fortuna crítica de No Me Olvides fue mucho más positiva con el paso de los años, convirtiéndola a ojos de la historiografía artística de nuestro país en una de las publicaciones más paradigmáticas del Romanticismo temprano atendiendo a cuestiones como su defensa de la arquitectura gótica, su enaltecimiento de lo popular y por ende de la idea de nación y su exaltación de los sentimientos. Aspectos, todos ellos, perfectamente apreciables no solo en los artículos publicados sino también en las estampas que los acompañaban, de las cuales procederemos a hablar a continuación.

\section{LOS GRABADOS EN NO ME OLVI- DES}

Como hemos dicho, la Litografía de Barrionuevo fue la responsable de estampar las once imágenes que No Me Olvides ofreció a sus lectores. Estas no fueron incluidas en la maquetación de las ocho páginas de cada entrega sino en unas láminas sueltas para que, en palabras del propio director, los lectores pudieran enmarcarlas con facilidad. El hecho de que se refiriera en estos términos a los grabados, iniciados por Federico de Madrazo mediante la técnica litográfica, pone de manifiesto hasta qué punto Salas y Quiroga no los consideraba un simple complemento estético del texto, sino auténticas obras de arte que poseían en sí mismas un gran interés artístico. Sin embargo, la partida de Madrazo al extranjero y su sustitución por Calixto Ortega provocaron una serie de cam- bios al respecto: mientras que las estampas del primero habían sido litografiadas, las del segundo fueron xilografiadas y poseían, por tanto, un grado de preciosismo mucho menor. De ahí que la calidad del papel tampoco fuera la misma, un cambio que quizás pudo deberse también a la preocupación de Salas y Quiroga por los escasos beneficios obtenidos por la publicación. De las once estampas que analizaremos a continuación, cinco son litografías (cuatro de Federico de Madrazo y una de Piero Augusto Guglielmi) y las otras seis xilografías (cinco de Calixto Ortega y una de un grabador desconocido).

\section{Federico de Madrazo (1815-1894)}

Resulta complicado resumir en unas pocas líneas la trayectoria del retratista más notable del Romanticismo español, por lo que nos conformaremos con trazar una breve semblanza suya antes de centrarnos en sus aportaciones a No Me Olvides. Nacido en 1815 en Roma, ciudad en la que su padre, José de Madrazo, se encontraba residiendo a la sazón como pintor de cámara del exiliado Carlos IV, estuvo inmerso desde sus primeros días en el ambiente profundamente artístico que caracterizó a esta dinastía de pintores, amén de disfrutar de la influencia de su padre desde el inicio de su carrera. Esta comenzó a despuntar en Madrid, ciudad en la que se instalaron los Madrazo en 1818 y en la que Federico, además de recibir una formación humanística, se empezó a relacionar con las que serían las grandes plumas del Romanticismo español al tiempo que acumulaba honores como el nombramiento de pintor supernumerario de cámara y académico de mérito de la Real Academia de Nobles Artes de San Fernando a la temprana edad de dieciséis años gracias a su cuadro $L a$ continencia de Escipión (1831).

Pese a que en sus primeros años resultara muy palpable su formación clasicista, claramente deudora del estilo de José de Madrazo, su propia evolución sumada a las influencias extranjeras que recibió durante sus estancias en Francia, Italia y Alemania lo 
acercaron cada vez más a los presupuestos románticos, que finalmente acabó abrazando con entusiasmo al convertirse en el retratista por excelencia de la aristocracia madrileña. Esto derivó en gran medida del hecho de que Isabel II decidiera nombrarlo primer pintor de cámara en 1857, uno de los cargos paternos "heredados" por Federico de Madrazo junto con el de director del Museo del Prado en 1860 y de la Real Academia de Nobles Artes de San Fernando en 1866. Además de obtener muchos más reconocimientos tanto nacionales como internacionales a lo largo de su vida, siguió también los pasos de José de Madrazo al convertirse en cabeza de una dinastía en la que encontramos a pintores de la siguiente generación como sus hijos Raimundo y Ricardo y su yerno Mariano Fortuny, pertenecientes los tres al movimiento realista ${ }^{13}$.

Nos encontramos, por tanto, ante un artista que se diferencia de Calixto Ortega en el hecho de que su principal medio de expresión no fue el grabado, sino los cuadros de retratos. Aun así colaboró con distintas publicaciones de la época como $\mathrm{No} \mathrm{Me} \mathrm{Ol}$ vides, llegando a dirigir, junto con su yerno Eugenio de Ochoa, la romántica El Artista entre 1835 y 1836 y la más atemperada $E l$ Renacimiento en 1847. En esta faceta suya, de nuevo, recurrió a la influencia de José de Madrazo, que había creado diez años antes el Real Establecimiento Tipográfico gracias a la obtención de una serie de privilegios concedidos por Fernando VII que le otorgaron el monopolio de la elaboración, impresión y difusión en nuestro país de estampas grabadas sobre piedra. De este establecimiento salieron las cuarenta y una realizadas por

${ }^{13}$ C. GONZÁleZ LÓPEZ, Federico de Madrazo y Küntz, Barcelona, 1981. Sobre el ascenso y poder de la familia Madrazo en los círculos artísticos españoles, C. GONZÁLEZ LÓPEZ y M. MARTÍ AYXELÀ, (coords.), El mundo de los Madrazo: colección de la Comunidad de Madrid. Catálogo de la exposición, Madrid, 2007; C. GONZÁlEZ LÓPEZ, “Los Madrazos: cuatro generaciones de artistas", Goya: Revista de arte, no 243, 1994, pp. 158-164 y J. I. SAMPERIO ITURRALDE, “Los Madrazo, el gen del éxito", Descubrir el arte, no 174, 2013, pp. 66-73.
Federico de Madrazo para El Artista, con unas características que, tal como veremos a continuación, son muy similares a las que grabó para No Me Olvides ${ }^{14}$.

Esencialmente, lo que se desprende de estas estampas es que nos encontramos ante un artista que está realizando pintura sobre piedra, desplegando el mismo virtuosismo que acabaría convirtiendo a sus cuadros en un símbolo de distinción para la aristocracia isabelina. Su tratamiento pictórico resulta muy distinto del que observaremos en el caso de los grabadores sobre madera, especialmente en cuanto a las gradaciones entre zonas de luz y de sombra, el tratamiento de las superficies iluminadas en los ropajes y, algo apreciable sobre todo en los retratos, la excelente plasmación psicológica. Cabe destacar también el aliento romántico de estas primeras litografías, muy acorde con el ideario de El Artista pese a que, si las comparamos con las obras salidas del pincel de Madrazo una década más tarde, observamos que por aquel entonces aún se encontraba adscrito a lo que podríamos denominar "clasicismo romántico", claramente deudor aún de muchos de los postulados del Neoclasicismo en el que el artista había comenzado su formación.

Si nos centramos en las cuatro litografías que realizó para No Me Olvides, todas ellas firmadas con las iniciales F. Mo. e impresas, a diferencia de las de El Artista, en la Litografía de Barrionuevo, comprobaremos que Salas y Quiroga tenía muy claro desde el primer momento la gran importancia que estas imágenes poseerían dentro de su publicación. De Madrazo es de hecho el frontispicio del primer tomo, una estampa realizada con

${ }_{14}$ A. GALLEGO GALLEGO, Historia del grabado en España, Madrid, 1991, p. 347; B. RODRÍGUEZ GUTIÉRREZ, "La voluntad iconográfica y aristocrática de El Artista", Revista de literatura, Vol. LXXIII, no 146, 2011, pp. 453-454 y J. M. FERRI COLL, "Las ilustraciones de El Artista y la idea de lo romántico en la década de 1830", en B. RODRÍGUEZ GUTIÉRREZ y R. GUTIÉRREZ SEBASTIÁN (coords.), Literatura ilustrada decimonónica: 57 perspectivas, Santander, 2011, pp. 245250 . 
lápiz, pincel y rascador en tinta negra que representa a una pareja despidiéndose en una puerta de reminiscencias góticas. Tanto este homenaje a la Edad Media tan admirada en No Me Olvides como la actitud sentimental de los protagonistas, aludiendo al nombre de la revista y el ya mencionado poema de José Joaquín de Mora, resultan profundamente románticos, si bien aún puede apreciarse en ellos ese eco clasicista característico del Madrazo de mediados de 1830. El mismo aliento melancólico puede observarse en otro grabado suyo ofrecido con el número del 20 de agosto de 1837 como acompañamiento de un texto de su hermano, el escritor, pintor y crítico de arte Pedro de Madrazo, titulado "Laura y Petrarca", aunque no está claro si este se inspiró en la estampa creada previamente por el artista o sucedió al revés ${ }^{15}$. Sea como fuere, de nuevo nos encontramos con una escena de cortejo que comparte con el texto el convencimiento, absolutamente romántico en sí mismo, de que en el siglo XIX era imposible cultivar un amor a la altura del de Francesco Petrarca y su musa.

Una fascinación similar por las épocas pasadas, algo que también está presente en los cuadros de historia creados por Madrazo antes de centrarse en la retratística, puede observarse en el grabado que acompañaba al texto "Una impresión supersticiosa" que vio la luz en el No Me Olvides del 2 de julio de 1837. De nuevo nos encontramos ante una colaboración de los hermanos Madrazo ambientada en una época imprecisa entre la Edad Media y el primer Renacimiento, a juzgar por el vestuario de los dos personajes, un joven sentado con actitud impaciente y una anciana de facciones ajadas, si bien no se trataba de la plasmación de una escena concreta del texto; el propio autor dejaba claro en las últimas líneas, de hecho, que el lector podía darle la interpretación que prefiriera.

Finalmente, la cuarta litografía de Federico de Madrazo, aparecida el 4 de junio de 1837 en la revista, es en la que podemos en-

15 M. E. RINCÓN CALERO, Las Fuentes del Romanticismo..., p. 287. contrar más semejanzas con los cuadros que harían de él uno de los principales pinceles del Madrid isabelino. A diferencia de los grabados anteriores, se trata de un retrato de medio busto de Juan Eugenio Hartzenbusch, del que ya dijimos que formaba parte del equipo de redactores de Salas y Quiroga, como acompañamiento de una biografía escrita por este último. Muy semejante en estilo y composición a otros retratos realizados por Madrazo para El Artista, como los de los arquitectos Juan de Herrera o Juan de Villanueva, no se basa en un retrato previo del escritor sino que probablemente fue creado del natural debido a la buena relación que ambos mantenían. Resulta evidente que Madrazo quiso conceder un protagonismo absoluto al rostro de Hartzenbusch, trabajado con una minuciosidad exquisita mientras que en la parte inferior de la composición encontramos unos trazos mucho más rápidos y abocetados. Buena parte de la levita y el chaleco, de hecho, están rellenos con un simple rayado, al igual que la débil sombra que se observa a la derecha del busto con la que pretendía otorgarle sensación de profundidad. En consecuencia, la excelente captación psicológica característica de los retratos de madurez de Madrazo ya se encuentra presente en este grabado de juventud, algo debido tanto a su talento innato como al hecho de que la técnica litográfica permitiera un preciosismo mucho mayor que la xilográfica, como también comprobaremos analizando la producción de Ortega.

\section{Calixto Ortega (1811-1860)}

La partida de Federico de Madrazo al extranjero en el otoño de 1837 convirtió a Calixto Ortega en el principal grabador de No Me Olvides. El propio Salas y Quiroga se refirió a este suceso en el ejemplar del 27 de agosto, informando a sus lectores de que tanto el pintor como su hermano Pedro se habían trasladado a París, "desde donde piensan salir á recorrer toda la Europa culta", una decisión que aplaudía a pesar de la tristeza de la separación por estar convencido de que poco tiempo después "los volve- 
remos sin duda á ver entre nosotros, ricos de gloria y de mas saber, y habremos dado por bien empleado el sacrificio que hemos hecho en separarnos de ellos"16. Dicho viaje tenía su origen en una pensión concedida por el Real Tesoro a Federico de Madrazo en 1830 tras pintar a los catorce años su cuadro $L a$ Resurrección del Señor; no obstante, el viaje quedó en suspenso hasta siete años más tarde, con la diferencia de que Madrazo decidió sustituir Roma por París y marcharse, además de con su hermano Pedro, con su esposa Luisa Garreta y su primogénita Luisa. De ahí partirían a Roma en 1840 y no regresarían a Madrid hasta 1842, momento en que Madrazo fue nombrado director de pintura de la Real Academia de Nobles Artes de San Fernando.

En lo concerniente a Calixto Ortega, nos encontramos con un artista que, pese a haberse convertido por aquel entonces en depositario de grandes esperanzas por parte de los amantes del arte, no acabó gozando del reconocimiento de Madrazo. Nacido en Lillo (Toledo) en 1811, en una familia de labradores, se trasladó doce años más tarde a Madrid para empezar a estudiar dibujo en la Academia, convirtiéndose una vez allí en protegido de José Aparicio, pintor de cámara de Fernando VII. Como sostiene Rincón Calero, la formación puramente neoclásica de Ortega en ambos círculos acabaría dando paso a un creciente interés por los postulados del Romanticismo, especialmente a partir de su interés por la técnica xilográfica y su implicación en ambientes culturales como el del Liceo Artístico y Literario Español y el de la tertulia de El Parnasillo en el Café del Príncipe, a la que concurrían desde 1829 autores tan reconocidos como Mariano José de Larra, José de Espronceda y Ramón de Mesonero Romanos ${ }^{17}$. Probablemente fue en estos

16 J. DE SALAS Y QUIROGA, "Viage", No Me Olvides, $\mathrm{n}^{-}$17, 27 de agosto de 1837, pp. 4-5.

17 M. E. RINCÓN CALERO, "Los primeros grabados de Calixto Ortega en las publicaciones literarias de 1837", en B. RODRÍGUEZ GUTIÉRREZ y R. GUTIÉRREZ SEBASTIÁN (coords.), Op.cit., p. 731. ambientes en los que Ortega pudo conocer a Jacinto de Salas y Quiroga, muy afín a los mentados escritores en cuanto a sus ideales románticos, y comenzar sus colaboraciones no solo con No Me Olvides, sino con otras publicaciones similares como Semanario Pintoresco Español y Observatorio Pintoresco.

Esa afición por el grabado en madera fue apartando progresivamente a Ortega de la pintura, de tal modo que en diciembre de 1837, apenas unos meses después de iniciar esa colaboración con No Me Olvides, aparecía citado como xilógrafo en el Libro de Actas de Juntas Ordinarias de la Academia con motivo de haberle sido concedido un cuarto para desarrollar esta labor en el Convento de la Trinidad, cedido al Museo Nacional ${ }^{18}$. Dos años más tarde partió también a París como había hecho Federico de Madrazo, con una pensión concedida en este caso por Pedro de Alcántara Téllez-Girón, IX duque de Osuna. Allí tuvo la oportunidad de profundizar en el estudio de la técnica xilográfica en la École des Beaux Arts y el taller de François Auguste Trichon, lo cual le permitió incluir en publicaciones periódicas francesas como Magasin Pittoresque algunos grabados que habían visto la luz previamente en otras españolas ${ }^{19}$.

Este período de formación duró hasta julio de 1840, cuando Ortega se instaló de nuevo en Madrid y empezó a ocuparse de numerosos encargos para revistas como $\mathrm{El}$ Renacimiento, Museo de las Familias, La Semana, La Ilustración, Álbum pintoresco, Museo de los Niños y La Risa, amén de continuar colaborando con Semanario Pintoresco Español. Mención especial merecen las xilografías que llevó a cabo para Los españoles pintados por sí mismos, recopilación de tipos populares publicada por el librero y editor Ignacio Boix entre 1843 y 1844 en la que colaboró con

${ }^{18}$ Ibídem, p. 732.

19 C. ALONSO, "La formación de la conciencia nacional en las primeras revistas ilustradas españolas (1836-1854)", en A. GIL NOVALES (coord.), La Revolución Liberal (Congreso sobre la Revolución Liberal española en su diversidad peninsular (e insular) y americana, Madrid, abril de 1999), Madrid, 2001, p. 617. 
otros artistas como Francisco Lameyer y Berenguer y Leonardo Alenza y $\mathrm{Nieto}^{20}$. En esa representación de distintos tipos populares, claramente deudora de Les français peints par eux-mêmes (1840-1842), puede apreciarse a la perfección cómo el estilo de Ortega se acercaba cada vez más al pintoresquismo, algo idóneo a la hora de plasmar cuadros de costumbres poseedores de un marcado carácter caricaturesco. Cabe citar también sus colaboraciones con otras obras de considerable importancia de las que años más tarde se haría eco Manuel Ossorio y Bernard, como Gil Blas (1840), Galeria regia y vindicación de los ultrajes extranjeros (1843-1845), Rienzi ó el ultimo tribuno (1843-1845), Historia de Zumalacárregui (1844), La España geográfica (1845), Los misterios de París (1845), El panorama español (1845) y Doce españoles de brocha gorda $(1848)^{21}$.

En lo concerniente a su estilo como grabador, la auténtica importancia de Ortega reside en el hecho de que perteneciera a esa primera generación de xilógrafos españoles que, para acabar con la dependencia de las revistas de nuestro país con respecto a los modelos e imaginario extranjeros, adquirieron una formación especializada que les hizo centrarse por completo en esta técnica en detrimento de la litográfica ${ }^{22}$. Comparar sus estampas con las de Federico de Madrazo equivale a comparar los logros que por aquel entonces se podían alcanzar mediante ambas modalidades: aunque menos preciosistas y minuciosos, los grabados sobre madera contaban con la enorme ventaja de la rapidez de ejecución y la posibilidad de ser incorporados en la misma página que el texto, si bien Salas y Quiroga optó por presentar los de Ortega como láminas independientes para que pudieran ser enmarcadas, tal como

${ }^{20}$ B. RIEGO, La construcción social de la realidad a través de la fotografía y el grabado informativo en la España del siglo XIX, Santander, 2001, p. 132 y J. VEGA GONZÁLEZ, Catálogo de estampas, Madrid, 1992, p. 140.

${ }^{21} \mathrm{M}$. OSSORIO Y BERNARD, Galería biográfica de artistas españoles del siglo XIX, II, Madrid, 1868, p. 85.

${ }^{22}$ B. RIEGO, Op. cit., pp. 132-133. había hecho con los de Madrazo ${ }^{23}$. Destacan en este sentido su tratamiento de las grandes masas oscuras, realizadas mediante una sucesión de líneas delgadas y paralelas trazadas a buril, así como la frecuente inclusión de figuras de pequeño tamaño ataviadas de manera popular con las que pretendía añadir una nota de pintoresquismo a sus escenas. La relación de Ortega con la estética costumbrista, de la que ya hemos hablado al referirnos a su colaboración con Los españoles pintados por sí mismos, quedó perfectamente plasmada en estas representaciones. En el caso de No Me Olvides la importancia recaía en la figura humana, mientras que en las xilografías que realizó para revistas como Museo de las Familias o Semanario Pintoresco Español lo más frecuente era que se centrara en la representación de monumentos para series como "España pintoresca", "España artística", etc. Cuando esto sucedía, Ortega, cuyas estampas aparecen firmadas tanto con su apellido como con Calisto Ortega, recurría a menudo a un punto de vista bajo destinado a magnificar la arquitectura, un encuadre similar a los empleados por artistas románticos como Eugenio Lucas Velázquez, especialmente cuando tenían que representar interiores de edificios religiosos.

Centrándonos en sus colaboraciones con No Me Olvides, encontramos que Ortega fue autor, como ya hemos mencionado, de cinco grabados, amén de hacerse cargo con bastante probabilidad de los pequeños grabaditos con forma de panoplias, cornucopias, etc., destinados a rellenar los huecos dejados por el texto. Su primera estampa apareció en el ejemplar del 17 de septiembre de 1837, acompañando a un poema de José Zorrilla titulado "La plegaria". Además de las diferencias estilísticas que hemos mencionado con respecto a la técnica litográfica, puede observarse de nuevo el interés del artista por lo pintoresco en la propia elección del tema, una madre rezando con su hijo a los pies de una cruz detrás de la cual per-

\footnotetext{
${ }^{23}$ M. E. RINCÓN CALERO, “Los primeros grabados de...", p. 737.
} 
manece embozado un hombre, ataviados los tres de manera popular. Sabemos, en relación con esto, que la estampa de Ortega fue anterior al texto de Zorrilla, pues el autor hace muchas alusiones a la misma ("Helos al pie de la cruz”, “¿Por qué, pintor, ideaste / una plegaria tan bella [...]?" ? $^{24}$. El mismo carácter popular puede apreciarse en la estampa "Recuerdos de un bautizo" aparecida en el ejemplar del 3 de diciembre de 1837 en relación con un relato de Sebastián López de Cristóbal; en ella podemos observar, con el acabado esquemático característico del buril, una escena desarrollada en el interior de una iglesia aparentemente románica en la que participan los padres del niño al que se bautiza, los padrinos, el sacerdote y el monaguillo. Este tipo de representación, adscrita a la contemporaneidad más estricta a juzgar por la vestimenta de los personajes y los objetos litúrgicos, se anticipa en cierta manera a obras de estilo realista como la célebre $L a$ vicaría pintada por Mariano Fortuny en 1870, poniendo de manifiesto cómo el Romanticismo con el que más comulgaba Ortega solía pasar, en muchas de sus colaboraciones con la prensa, por el filtro del costumbrismo.

No obstante, No Me Olvides también cuenta con grabados suyos en los cuales la contemporaneidad desaparece por hacer referencia a personajes o escenas del pasado. Es el caso del retrato de Antonio Pérez del Hierro, secretario de Felipe II, cuya relación dio pie al drama que José Muñoz Maldonado, conde de Fabraquer, estrenó ese otoño. No Me Olvides se había referido a ello con una breve nota aparecida en el ejemplar del 15 de octubre de 1837, publicando dos semanas más tarde una crítica no del todo elogiosa rubricada por el propio Salas y Quiroga. En lo tocante a la estampa de Ortega, pone de manifiesto cómo su talento como retratista era evidentemente menor que el de Federico de Madrazo: a la absoluta falta de naturalidad del busto de Pérez del Hierro se suma una notable torpeza en la recreación

${ }^{24}$ J. ZORRILLA, “La plegaria”, No Me Olvides, no 20, 17 de septiembre de 1837, p. 4. del cabello, los pliegues de la gola y el brillo de los ropajes, defectos comprensibles si tenemos en cuenta que Ortega se había especializado en escenas en las que aparecían numerosos personajes situados a una mayor distancia del espectador, no en el género pictórico que acabó convirtiendo a Madrazo en uno de los principales pinceles del Romanticismo en nuestro país. Más acertada resulta la composición del otro grabado de época que realizó para No Me Olvides, publicado el 21 de enero de 1838 como complemento de un texto titulado "El retrato", probablemente del mismo Sebastián López de Cristó$\mathrm{bal}^{25}$. En ella, Ortega vuelve a remontarse a comienzos del siglo XVII a juzgar por los ropajes de la mujer acomodada en un asiento y el hombre cabizbajo al que está interpelando, aunque López de Cristóbal no mencione en ningún momento cuándo se desarrollaba esta acción.

Finalmente, la última xilografía realizada por Ortega para No Me Olvides consiste en la representación de una de las puertas de la Alhambra de Granada, concretamente la conocida como Puerta del Vino a través de la cual podía accederse a la Alhambra alta o Medina. Esta estampa resulta algo más peculiar porque solo aparece en dos ejemplares de No Me Olvides del 14 de enero de 1838 conservados en la Biblioteca Nacional y en el microfilmado de la Hemeroteca Municipal de Madrid ${ }^{26}$. En este caso no se trataba de una estampa realizada expresamente por Ortega para esta publicación, puesto que había visto previamente la luz en el Observatorio Pintoresco del 15 de julio de 1837 como acompañamiento del poema "Recuerdos de Granada" del jurista e historiador Nicolás Peñalver y López ${ }^{27}$. Pese a ser deudora de la

\footnotetext{
${ }^{25}$ P. CABAÑAS, Op. cit., p. 136.

26 M. E. RINCÓN CALERO, Las Fuentes del Romanticismo..., p. 294.

27 N. PEÑALVER Y LÓPEZ, "Puerta de la Alhambra", Observatorio Pintoresco, 15 de julio de 1837 , volumen I, no 11,15 de julio de 1837 , p. 88 . Este poema había sido publicado cuatro años antes por la imprenta granadina de Francisco Benavides con el
} 
calcografía realizada tres años antes por el pintor escocés David Roberts, pueden apreciarse en la estampa las mismas características que en la mayoría de las que Ortega realizó de monumentos españoles, tanto en lo tocante a la plasmación de los distintos elementos arquitectónicos como a la inclusión de sus figurillas de carácter costumbrista. El toque romántico, en este caso, no entronca solamente con el pintoresquismo sino también con el exotismo que estaba empezando a calar hondo en la España isabelina, sumado a la ya mencionada fascinación por las obras de arte que se consideraban símbolos de la nación.

\section{OTROS GRABADORES}

No podemos dejar de mencionar la existencia de otros dos grabados que vieron la luz en No Me Olvides, aunque el hecho de que no se hiciera referencia a los mismos en la revista y solo hayan sido incluidos en la encuadernación de uno de los ejemplares de la Biblioteca Nacional no nos permite estar seguros de que realmente fueran concebidos para esta publicación y, de ser así, en qué números se incluyeron ${ }^{28}$. La primera de esas láminas consiste en un retrato de la célebre actriz Matilde Díez realizado mediante la técnica litográfica, una representación que vuelve a encontrarse muy lejos de la perfección alcanzada por Madrazo en su retrato de Hartzenbusch y en la cual el toque romántico deriva únicamente de la colocación de la dama delante de una arquería apenas esbozada de resabios góticos. Fue realizada por Piero Augusto Guglielmi ${ }^{29}$, un miniaturista y litógrafo activo durante la primera mitad de la centuria decimonónica del que solo se sabe que fue mandado llamar a nuestro

título Pensamiento poético de D. Nicolás Peñalver y López con que esta M.N. y M.L. ciudad de Granada, adornó la plaza de Bib-Rambla en la solemnidad del Santísimo Sacramento en este año de 1833.

28 M. E. RINCÓN CALERO, Las Fuentes del Romanticismo..., p. 294.

${ }^{29}$ Cabañas cita erróneamente su apellido como “Guglielni". P. CABAÑAS, Op. cit., p. 137. país por José de Madrazo entre 1826 y 1837, junto con su hermano Paolo y otros artistas extranjeros como Léon Auguste Asselineau, Victor Alexis, François Bellay, Ludwig Theodor Zöllner y Cayetano Palmaroli, para formar parte de su ambicioso proyecto Colección litográfica de cuadros del Rey de España D. Fernando VII ${ }^{30}$. El hecho de que esta colaboración concluyera el mismo año que empezó a publicarse el No Me Olvides, sumado a la relación de Guglielmi con el clan de los Madrazo y, por extensión, con el círculo del que también formaba parte Salas y Quiroga, permite entender por qué pasó a formar parte de su equipo de grabadores aunque fuera solo con una colaboración, posiblemente debido a la escasa duración de la revista. Cabe mencionar que tampoco en este caso nos encontramos con una litografía publicada solo en No Me Olvides, pues volvería a ver la luz en 1840 en la revista valenciana El Cisne $e^{31}$.

En cuanto a la segunda lámina incluida en el ejemplar de la Biblioteca Nacional sin precisar su colocación, acusa las influencias del Romanticismo meramente epidérmico en cuanto a la propia temática: un hombre escribiendo ante una mesa y una muchacha apoyándose en su brazo, conformando una estampa impregnada de la sensibilidad más característica de la década de 1830 pese a que, en este caso, desconozcamos al autor ${ }^{32}$.

\section{CONCLUSIONES}

El análisis que hemos llevado a cabo de los grabados de No Me Olvides arroja una serie de interesantes conclusiones relativas al papel desempeñado por esta publicación en la forja del Romanticismo español y, por extensión, a la situación de indefinición que se estaba dando en los círculos culturales

30 M. C. ESPINOSA MARTÍN, Iluminaciones, pequeños retratos y miniaturas en la Fundación Lázaro Galdiano, Madrid, 1999, p. 281.

${ }^{31}$ Á. M. BARCIA, Catálogo de los retratos de personajes españoles que se conservan en la Sección de Estampas y de Bellas Artes de la Biblioteca Nacional, Madrid, 1901, pp. 551-552.

\footnotetext{
${ }^{32}$ P. CABAÑAS, Op. cit., p. 136.
} 
del país cuando comenzó a ver la luz. Como punto de partida, no podemos dejar de recordar que pasa por ser la más romántica de las primeras revistas artísticas de época isabelina, mostrando durante sus escasos meses de vida un intenso compromiso con este movimiento derivado del propio posicionamiento de su director. Efectivamente, Salas y Quiroga dictó la pauta seguida por el resto de su equipo en cuanto al contenido del rotativo (recordemos que actualmente se considera que su prospecto es uno de los grandes manifiestos del Romanticismo literario español), pero también en lo relativo a su formato. En este sentido, pueden apreciarse claramente sus intentos por conseguir que el continente de No Me Olvides estuviera a la altura de su contenido, sirviéndose para ello de las ventajas del grabado con un entusiasmo que hizo de esta publicación una pionera entre las españolas en cuanto a la inclusión de estampas.

No obstante, en relación con la indefinición de la que hablábamos, conviene tener en cuenta que no existió una sensibilidad romántica unívoca en dichos grabados. Todas las dudas y tentativas que se estaban dando al final de la década de 1830 se encuentran presentes en ellos, con los distintos artífices apostando por una $\mathrm{u}$ otra tendencia como consecuencia de su propia evolución. Si bien existen ciertos elementos presentes desde el primer número de la revista (como las composiciones de reminiscencias góticas, o el tono decididamente sentimental de algunas de las escenas), los principales grabadores del equipo, Madrazo y Ortega, supieron alejarse de lo epidérmico para contribuir, cada uno a su modo, a la configuración de lo que acabaría siendo el auténtico Romanticismo.

En el caso del primero, como también hemos mencionado ya, encontramos que su estilo se hallaba en aquella época en una especie de puente entre la tradición académica en la que se había formado y los presupuestos románticos que acabaría abrazando en su etapa de plenitud como principal retratista de la aristocracia madrileña. De ahí que las estampas que hemos analizado todavía se muestren deudoras de las creadas por artistas de la generación anterior como José de Madrazo; sirvan como ejemplo la pureza de los contornos, la delicadeza de las actitudes, muy alejadas de los arrebatos pasionales del Romanticismo maduro, y la magnífica plasmación psicológica en los retratos. Hemos de recordar de nuevo que esta característica concreta acabaría siendo la que le brindaría los laureles de la fama a Federico de Madrazo, una vez decidiera centrarse en dicho género.

Muy distintas son las estampas creadas por su sucesor Ortega, y no solamente en lo tocante a la técnica. Si bien no se encuentran pictóricamente hablando a la altura de las de Madrazo, sus xilografías acusan una mayor cercanía en cuanto a su temática a los presupuestos auténticamente románticos. El academicismo desaparece por completo en ellas dando paso al costumbrismo, uno de los grandes intereses de Ortega; de ahí que en sus composiciones lo sentimental ceda terreno ante lo realista, prestando además una especial atención a la ropa contemporánea, los tipos populares, las costumbres locales y todo aquello que resultara pintoresco. En esta misma línea, aunque no realizara para No Me Olvides tantas xilografías de este tipo como para otras publicaciones, se hallarían las representaciones de los principales monumentos españoles, una iniciativa frecuente en revistas como Semanario Pintoresco Español derivada del creciente sentir nacionalista que convertía a estos edificios en enseñas de un pasado digno de admiración. En el caso de los monumentos andalusíes, el nacionalismo compartía protagonismo con otro de los principales rasgos del Romanticismo pleno: la pasión por el exotismo responsable de que en la Europa decimonónica nuestro país fuera considerado una puerta abierta a Oriente.

Finalmente, los otros dos grabadores que colaboraron con No Me Olvides, uno de ellos anónimo y el otro Piero Augusto Guglielmi, no protagonizaron una apuesta tan clara por una tendencia $\mathrm{u}$ otra como Madrazo y Ortega. Sus estampas se limitaron 
a incluir esos elementos recurrentes de los que hemos hablado como arquerías góticas y actitudes sentimentales, propias de un Romanticismo más impersonal. En cualquier caso, tanto esta variante como las anteriormente citadas ponen de manifiesto el afán de No Me Olvides por abrazar desde sus mismos inicios los postulados de este movimiento. Academicismo romántico, costumbrismo, nacionalismo y exotismo no son sino algunas de las caras de un estilo caracterizado por su personalidad multifacetada, algo apreciable tanto en la literatura como en las artes pese a que, como quedó plasmado en el caso de esta revista, los poderosos cambios de los que se hizo eco Salas y Quiroga irrumpieran unos años antes en el panorama literario, de ahí los distintos criterios de sus grabadores.

\section{BIBLIOGRAFÍA}

ALONSO, C., "La formación de la conciencia nacional en las primeras revistas ilustradas españolas (1836-1854)", en A. GIL NOVALES, La Revolución Liberal (Congreso sobre la Revolución Liberal española en su diversidad peninsular (e insular) y americana, Madrid, abril de 1999), Madrid, 2001, pp. 611-634.

BARCIA, Á. M., Catálogo de los retratos de personajes españoles que se conservan en la Sección de Estampas y de Bellas Artes de la Biblioteca Nacional, Madrid, 1901.

BLANCO MARTÍN, M. Á., “Opinión pública y libertad de prensa (1808-1868)", en J. SIMOZ DÍAZ (coord.), La prensa española durante el siglo XIX. I Jornadas de especialistas en prensa regional y local, Granada, 1988, pp. 27-52.

BOZAL, V., La ilustración gráfica del siglo XIX en España, Madrid, 1979.

CABAÑAS, P., No me olvides (Madrid, 18371838), Colección de índices de publicaciones periódicas dirigida por Joaquín de Entrambasaguas, II, Madrid, 1946.
ESPINOSA MARTÍN, M. C., Iluminaciones, pequeños retratos y miniaturas en la Fundación Lázaro Galdiano, Madrid, 1999.

FERRI COLL, J. M., "Las ilustraciones de $E l$ Artista y la idea de lo romántico en la década de 1830", en B. RODRÍGUEZ GUTIÉRREZ y R. GUTIÉRREZ SEBASTIÁN (coords.), Literatura ilustrada decimonónica: 57 perspectivas, Santander, 2011, pp. 245-250.

GALLEGO GALLEGO, A., Historia del grabado en España, Madrid, 1991.

GARCÍA MELERO, J. E., Literatura española sobre artes plásticas, II, Bibliografía aparecida en España durante el siglo XIX, Madrid, 2002.

GONZÁLEZ LÓPEZ, C., Federico de Madrazo y Küntz, Barcelona, 1981.

"Los Madrazos: cuatro generaciones de artistas", Goya: Revista de arte, no 243, 1994, pp. 158-164.

GONZÁLEZ LÓPEZ, C. y MARTÍ AYXELÀ, M. (coords.), El mundo de los Madrazo: colección de la Comunidad de Madrid. Catálogo de la exposición, Madrid, 2007.

HENARES CUÉLLAR, I. y CALATRAVA, J., Romanticismo y teoría del arte en España, Madrid, 1982.

HURTADO TORÁN, E., Las publicaciones periódicas de Arquitectura, Madrid, 2001.

ISAC, Á., Eclecticismo y pensamiento arquitectónico en España. Discursos, revistas, congresos (1846-1919), Granada, 1987.

MONGUIÓ, L., Don Jose Joaquin de Mora, Los Angeles, 1967.

OSSORIO Y BERNARD, M., Galería biográfica de artistas españoles del siglo XIX, II, Madrid, 1868.

PAJARES INFANTE, E., "Traducción en la emigración. Pablo de Mendibil y su No me olvides de 1828", en C. PALACIOS BERNAL, F. LAFARGA y A. SAURA SÁNCHEZ (coords.), Neoclásicos y román- 
ticos ante la traducción, Murcia, 2002, pp. 73-88.

PEÑALVER Y LÓPEZ, N., "Puerta de la Alhambra", Observatorio Pintoresco, volumen I, no 11, 15 de julio de 1837, p. 88.

PLAZAOLA, J., Modelos y teoría de la Historia del Arte, San Sebastián, 2009.

RIEGO, B., La construcción social de la realidad a través de la fotografía y el grabado informativo en la España del siglo XIX, Santander, 2001.

RINCÓN CALERO, M. E., “De la ficción a la historia: la biografía del viajero romántico Jacinto de Salas y Quiroga", Crítica hispánica, Vol. XXXI, nº 2, 2009, pp. 187-203.

- "Los primeros grabados de Calixto Ortega en las publicaciones literarias de 1837”, en B. RODRÍGUEZ GUTIÉRREZ y R. GUTIÉRREZ SEBASTIÁN (coords.), Literatura ilustrada decimonónica: 57 perspectivas, Santander, 2011, pp. 729-740.

"Periodismo y literatura en el Romanticismo. El periódico literario $\mathrm{No} \mathrm{Me} \mathrm{Ol}$ vides (1837-1838)", en J. M. RODRÍGUEZ RODRÍGUEZ y M. ANGULO EGEA (coords.), Periodismo literario: naturaleza, antecedentes, paradigmas y perspectivas, Madrid, 2010, pp. 71-87.

Las Fuentes del Romanticismo en España: No Me Olvides. Periódico de Literatura y Bellas Artes, Tesis doctoral defendida en The Ohio State University (en línea), consultado el 31 de marzo de 2017. URL: https:// etd.ohiolink.edu/!etd.send_file?accession =osu1243974459\&disposition=inline.

RODRÍGUEZ GUTIÉRREZ, B., "La voluntad iconográfica y aristocrática de $E l A r$ - tista", Revista de literatura, Vol. LXXIII, $\mathrm{n}^{\mathrm{o}}$ 146, 2011, pp. 449-488.

ROMERO TOBAR, L., Panorama crítico del romanticismo español, Madrid, 1994.

ROSEN, C. y ZERNER, H., Romanticismo y realismo. Los mitos del arte del siglo XIX, Madrid, 1988.

SALAS Y QUIROGA, J. de, "Prospecto", No Me Olvides, no 1, 7 de mayo de 1837, pp. 1-3.

_- "Viage", No Me Olvides, no 17, 27 de agosto de 1837 , pp. 4-5.

SAMPERIO ITURRALDE, J. I., "Los Madrazo, el gen del éxito", Descubrir el arte, $\mathrm{n}^{\circ}$ 174, 2013, pp. 66-73.

SEBOLD, R. P., “Jacinto de Salas y Quiroga, poeta huérfano, cosmopolita y romántico", Salina. Revista de Lletres, no 23, 2009, pp. 67-78.

TAJAHUERCE ÁNGEL, I., El arte en las revistas ilustradas madrileñas (1835-1840), Tesis doctoral defendida en la Universidad Complutense de Madrid, 2004.

TORRES NEBRERA, G., "La poesía del bardo sombrío Salas y Quiroga", en Aún aprendo. Estudios dedicados al profesor Leonardo Romero Tobar, Zaragoza, 2012, pp. 259-268.

— "Salas y Quiroga, Jacinto de", en Diccionario Biográfico Español, XLV, Madrid, 2013, pp. 186-187.

VEGA GONZÁLEZ, J., Catálogo de estampas, Madrid, 1992.

ZORRILLA, J., "La plegaria”, No Me Olvides, no 20, 17 de septiembre de 1837, pp. 3-4. 